I Consejo Nacional de Investigaciones Científicas y Técnicas (CONICET)

Universidad Nacional de Mar del Plata (UNMdP), Mar del Plata, Argentina

gasgil@mdp.edu.ar

https://orcid.org/oooo-0002-8I I 2-2 I I 9

Gastón Julián Gil'

\title{
MORALIDAD, VIRTUD Y EMOCIONES EN EL RUNNING. APROXIMACIONES ETNOGRÁFICAS DE UN ESTILO DE VIDA EN LA ARGENTINA CONTEMPORÁNEA
}

\section{BELLEZA, ESFUERZO Y VIRTUD}

"La vida es como el ejercicio. Cuanto más duro es, más fuerte te vuelves." Una amplia variedad de esta clase de mensajes circula a modo de adhesión por los perfiles y biografías de los corredores en las redes sociales. En efecto, la elección de correr con regularidad y sistematicidad implica aspectos mucho más relevantes que volcarse a una práctica deportiva. El running, en tanto fenómeno que interpela a esta clase de deportistas amateurs de las más diversas edades, puede definirse como un estilo de vida que envuelve un amplio y denso conjunto de aristas éticas y estéticas (Gil, 20I8). Los runners suelen acompañar sus experiencias atléticas (principalmente entrenamientos y carreras) con marcadas estilizaciones, pero sobre todo con una sobrecarga emocional que conforma un universo moral y discursivo de complejidad. Así, movilizan una serie de repertorios morales sustentados en preceptos éticos (voluntad, autosuperación, constancia) y estéticos (liviandad, belleza, armonía) que garantizarían una amplia variedad de beneficios para una vida mejor, cargada de emociones positivas y más bella.

En efecto, es usual que cualquier grupo se distinga de otros invocando diferencias de orden moral, adjudicándose virtudes de las que carecen los demás (Sayer, 2005). Como se podrá apreciar en este artículo, los runners apelan de forma más o menos explícita y con diferente énfasis a toda una serie de preceptos virtuosos que los definen y que permiten establecer fronteras iden- 
titarias hacia dentro y hacia afuera del propio colectivo de corredores. Poseedoras de atributos que se encuentran al alcance de quien desee encarnarlas, las moralidades que se cristalizan en el running constituyen un campo de análisis sumamente fructífero.

El running constituye un fenomeno que ha experimentado un crecimiento exponencial a escala global y que no da signos de agotamiento. Las estadísticas, al menos en Occidente, señalan un incremento sostenido desde hace décadas de la cantidad de participantes en las diversas modalidades de carreras. Algunas de ellas son de una masividad tal que se hace necesario establecer cupos estrictos, como ocurre con la maratón de Nueva York, que se trata además de un evento de un importante impacto turístico. En Brasil también se registra un crecimiento exponencial del running en la última década. Los inscriptos anuales en carreras de calle llegan casi a los cinco millones y, por ejemplo, en el Estado de São Paulo se organizan casi 400 carreras por año (Dias, 2017).

En el caso argentino, y particularmente en la ciudad de Mar del Plata, ${ }^{\mathrm{I}}$ donde se lleva a cabo el trabajo de campo, tambien se puede registrar una adhesión masiva. Sus costaneras, boulevards, plazas y demás paseos urbanos, se pueblan todos los días, y durante cualquier horario, de corredores solitarios y grupales. En su gran mayoría, no son atletas de competición, algunos tal vez lo hacen como complemento aeróbico para la práctica de otros deportes, pero en su mayor parte son runners y lo hacen acompañados por otros miembros de sus running teams, que le dan un soporte formal a la práctica de correr.

La visibilidad de estos grupos es cada vez más notoria y ya es todo un lugar común que a cualquier corredor se le pregunte "en dónde entrenás". Inclusive los formularios de inscripción a las carreras suelen contener un espacio para referir a la membrecía de un running team, y los resultados oficiales luego reflejan esa información. De hecho, algunas competencias contemplan los resultados por equipo, que los triunfadores promocionan orgullosamente en las redes sociales. En la ciudad de Mar del Plata no se conoce ningún registro oficial, pero no menos de 50 de estas agrupaciones suelen ser representadas por sus corredores en las diversas competencias organizadas en la ciudad.

A partir de los running teams se conforman y consolidan distintas relaciones de amistad o de pareja (estables y pasajeras) cimentadas, en principio, por las exigentes jornadas de entrenamiento. Los dominios culturales como pueden ser los hábitos alimenticios, horarios de salidas nocturnas y eventos atléticos, tienden a confluir cada vez con mayor frecuencia, como también los temas de las conversaciones y otras afinidades que se pueden llegar a establecer.

En este artículo se analizan entonces las moralidades movilizadas por el running en Argentina. Los datos provienen de la etnografía multi-situada (Marcus, I995) que tiene su centro en la ciudad de Mar del Plata. El trabajo de campo tiene uno de sus focos en dos grupos de entrenamiento de esta ciudad, pero se expande hacia una comunidad nacional (y eventualmente transacional) de corredores 
que se movilizan constantemente en torno a las diversas carreras en las que participan. Así es que por más de dos años se han compartido carreras, entrenamientos y largos viajes a competencias en diferentes y alejados lugares del país.

Se desarrolla también una etnografía virtual (Hine, 20I7), dada la centralidad de las redes sociales (fundamentalmente Facebook e Instagram) en la difusión de las actividades de los grupos de corredores, la organización de las carreras y la circulación discursiva en el running. Además, se utilizan herramientas y conceptos de la semiótica (en especial la teoría de enunciación) para analizar la discursividad que caracteriza a los corredores. De ese modo, se pretende dar cuenta del conjunto de configuraciones emocionales que expresan los corredores en el marco de un estilo de vida altamente moralizado y estilizado. Se presentará entonces al running como una tecnología de autogobierno que moviliza comportamientos, relaciones y sentimientos ideales que definen los parámetros fundamentales de un "verdadero" corredor.

\section{ESTILOS DE VIDA Y MORALIDAD}

Conceptualizar al running como un estilo de vida permite enmarcarlo como un “conjunto de prácticas más o menos integrado que un individuo adopta no sólo porque satisfacen sus necesidades utilitarias, sino también porque dan forma material a una crónica concreta de la identidad del yo" (Giddens, I995: I06). El running se configura entonces como uno de tantos repertorios potenciales que, en este caso, se caracteriza por una marcada estilización de la vida, traducida en determinadas opciones de consumo, la adopción de un estética definida y la búsqueda de experiencias vitales y trascendentes para la realización personal (Chaney, I996). Los estilos de vida pueden ser vivenciados y narrados por los sujetos como un marco de comportamientos personales que eligen con completa libertad, dado que les proporcionan una historia acerca del modo en que eligen, por ejemplo, cómo vestirse y alimentarse, lo que se consume o cómo se utiliza el tiempo libre. En este caso los corredores, tal cual se intentará mostrar, suelen presentarse como individuos "libres" que adoptan decisiones clave referidas "no sólo a cómo actuar, sino a quién ser" (Giddens, I995: I06).

Ello nos lleva necesariamente a recuperar categorías centrales del pensamiento social referidas de manera principal a la noción de individuo. Como destacara Norbert Elias (20 I : 37) “'individuo' y 'sociedad' no se remiten a dos objetos con existencia separada, sino a aspectos distintos, pero inseparables, de los mismos seres humanos". Así es que en esta perspectiva "el problema de las relaciones entre estructuras individuales y estructuras sociales comienza a aclararse en la medida en que se investigan ambas como algo mutable, como algo que está en flujo continuo" (Elias, 200I: 37). Al proponer "una 'interpenetración' entre individuo y sistema social" (Elias, 20I I: 37), rechaza considerar al individuo como algo externo u opuesto a la sociedad, lo que permite escapar de esos binarismos y reduccionismos que suelen oscurecer la teoría social. 
En efecto, mostrar al "individuo más allá de la sociedad, y a la sociedad como un sistema fuera y más allá del individuo" (Elias, 20 I I: 59) obtura la posibilidad de entender a la sociedad como un "entramado de interdependencias constituido por los individuos" (Elias, 20I I: 70), que dan lugar a lo que este autor denominó figuraciones sociales. Estas figuraciones no son otra cosa que sujetos "orientados recíprocamente y mutuamente dependientes" (Elias, 20 I I: 70), en el marco de cuyos cambios también se modifican las estructuras de personalidad. A través de estas estructuras psicológicas individuales se ejerce determinado control de las emociones y un conjunto de actitudes de los individuos hacia sí mismos y hacia los demás.

El deporte en general "ha llegado a constituirse en una de las claves que dan sentido a las vidas de muchas personas" (Elias \& Dunning, I992: 266). El running no sólo lo expresa con firmeza sino que también es una de "las principales fuentes de emoción agradable" (Elias \& Dunning, I992: 266) para sus aficionados, que encuentran en este estilo de vida un modo de expresión virtuoso y repleto de belleza cotidiana. Esa opción por correr se experimenta y se expresa fuertemente moralizada, dado que los runners la acompañan con un conjunto de postulados axiológicos que apuntan a destacar acciones y decisiones virtuosas, en contraste con otros modos posibles de afrontar la vida. La afición por el running podría ser definida desde afuera como una adhesión altamente sacrificada (por sus compromisos familiares y laborales) pero los corredores suelen destacar otras dimensiones más vinculadas con el disfrute personal y grupal. Como lo hizo Cachito en una oportunidad en las redes sociales, se suele colocar el énfasis en la importancia de "compartir con amigos y disfrutar esta carrera" que "es una fiesta que no tiene precio". Esa frase ilustraba una foto de la organización de la competencia en donde aparecía subiendo una loma característica de Mar del Plata con su compañero más cercano de entrenamiento y carreras, en actitud risueña y relajada cerca de completar los $2 \mathrm{I}$ kilómetros de una media maratón.

El mismo corredor, luego de otra carrera, se animó incluso a teorizar en Facebook sobre las "propiedades del running. Así, elaboró la siguiente lista en la que combina beneficios concretos, actos virtuosos, emociones y firmes proclamas morales: "Principalmente conocer muchos amigos", "Ir a un grupo de entrenamiento", "Calidad de vida”, "Anotarme en muchas carreras", “Conocer lugares y muchos", "Proponerte distancias más largas que jamás imaginaste", "Participación de la familia en tus llegadas", "Dar un ejemplo para tus hijos", "No hace falta hacer dieta", "Reunión con tus amigos del grupo a comer asado, pizza, cervesa etc.", terminando con "correr en 44 minutos una carrera de rok". Finalmente enunciaba en complicidad: "Que más querés para empezar".

Por supuesto que todos los esfuerzos que cotidianamente realiza un corredor (como entrenar con disciplina, resignar horas de sueño, diversión nocturna o las privaciones en las comidas) son incomparables con los resultados 
que se invoca obtener: sentirse mejor, una salud de calidad y, sobre todo, la felicidad, el placer y la belleza en el correr.

Las moralidades que se movilizan en torno al running nos colocan frente a una variedad de configuraciones emocionales que envuelven la opción por correr como un estilo de vida. Ello es especialmente relevante en nuestra contemporaneidad dado que "las ideas son imbuidas de emocionalidad y, a la inversa, el modo en que las emociones han absorbido un contenido conceptual, narrativo y ficcional. Este proceso forma parte de aquello que he denominado imaginación ficcional-emocional" (Illouz, 20I 2: 273). Además, las emociones vinculadas con las prácticas lúdicas y deportivas pueden ser interpretadas como "el complemento y la antítesis" (Elias \& Dunning, I992: 95) de las actividades formales e institucionalizadas de la vida cotidiana.

El running no sólo dispone de una gran cantidad de rituales de interacción (Collins, 2004) que cargan de energía a sus aficionados (sobre todo las carreras) sino que moviliza un amplio conjunto de emociones, entendidas como aquellos sentimientos que los individuos dirigen hacia los otros en las interacciones sociales y que se objetivan en el marco de esos procesos intersubjetivos. Las emociones "se cristalizan en códigos de moralidad, memorias, jerarquías y fronteras sociales, en proyectos individuales y colectivos" (Borges Barbosa, 2016: 200). Pero sobre todo, las emociones se configuran como "la energía interna que nos impulsa en un acto" (Illouz, 2007: I5). En esa línea, Illouz se refiere a una "ontología emocional" (Illouz, 20I2), en tanto que sistema de representaciones que permiten el monitoreo de las relaciones, estableciendo ideales y evaluando permanentemente aquellas relaciones propias y ajenas sobre la base de esos parámetros.

Estas evaluaciones ontológicas de la vida cotidiana no están sostenidas mayormente en las experiencias concretas de los sujetos, sino que toman como referencia "constante y tácita" (Illouz, 20 I2: 295) a los modelos normativos que las preexisten, en tanto ejemplos morales que se corresponden con la imaginación ficcional-emocional. Fundamentalmente, "las emociones son aspectos profundamente internalizados e irreflexivos de la acción, pero no porque no conlleven suficiente cultura y sociedad, sino porque tienen demasiado de ambas" (Illouz, 2007: I6).

El running es continuamente postulado por sus adherentes como una poderosa fuente de energía emocional que permite escapar de aquellos sentimientos negativos que persiguen a los individuos en su vida cotidiana, tales como la vergüenza, la ira o el resentimiento, y que refieren a ominosos quiebres morales. Sin embargo, el running también puede, y de hecho lo hace en muchos casos, favorecer sentimientos "negativos", como la frustración. Las lesiones (recurrentes o esporádicas, leves o graves), los malos rendimientos, los escasos avances (aun con entrenamientos intensivos mediante) son algunas de las fuentes habituales de frustración que son difíciles de superar para quien se vuelca con pasión al running. 


\section{MORAL Y TEORÍA ANTROPOLÓGICA}

La reflexión antropológica sistemática sobre la moralidadha experimentado cierta vitalización en las últimas décadas, que ha posibilitado la conformación de "una antropología de la moral o lo moral como campo específico de indagación" (Noel, 20I4: I8). Uno de los problemas habituales ha sido la inespecificidad de la noción de moral, que se ha ido confundiendo con otras categorías de peso en el pensamiento antropológico, tales como ritual, cultura o incluso religión (Zigon, 2008). Esa escasa teorización derivó en usos erróneos del concepto, como la tendencia a imponer las nociones occidentales sobre el mal o la virtud en diferentes contextos culturales.

Si bien no puede decirse que las dimensiones morales estuvieran completamente ausentes en la producción antropológica clásica, la tematización específica en torno a este concepto es relativamente novedosa. En ese sentido, la compilación Ethnography of moralities (Howell, I997) constituye un punto de referencia insoslayable. Ello tiene especial vinculación con el deporte, dado que una de las contribuciones (Eduardo Archetti, I997) está relacionada con el fútbol argentino. ${ }^{2}$ En la introducción de aquel libro, Howell (I997) aboga por un estudio transcultural de las moralidades que muestre los procesos de reflexión mediante los cuales los individuos deciden entre alternativas de opción eventuales. De ese modo, los distintos capítulos muestran la relevancia de considerar los casos particulares en diversos contextos etnográficos que dan cuenta de aquellas sutilezas que configuran la vida moral de los sujetos de estudio. Entonces, "focalizan en la moralidad como un ámbito que no se caracteriza por el seguimiento de las reglas, sino por las experiencias vividas que se retroalimentan entre sí en un proceso continuo de reevaluación y puesta en práctica" (Zigon, 2008: 9).

En aquellas investigaciones, la moralidad es analizada en líneas generales como una reflexión acerca de lo que es bueno o malo, correcto o incorrecto, y se cristaliza en las respuestas e interpretaciones que los individuos dan ante situaciones concretas de la vida cotidiana. Así, se movilizan acciones y creencias que dan cuenta de esos códigos morales pero también de los actores y de los contextos (Archetti, I997, I 999). Archetti (I 999) encuadra la moralidad en torno a cómo narramos y le damos forma y sentido a nuestras vidas y cómo discutimos esas narrativas. Los discursos morales de los actores sociales:

crean una escena en la cual están disponibles símbolos y narrativas históricas, nuevas experiencias relacionadas con situaciones dadas, imágenes y resultados deportivos, nuevas preguntas, respuestas a esas preguntas y juicios acerca de la corrección de todas esas respuestas mezcladas entre ellas (Archetti, I999: 125).

Las moralidades suelen ser contradictorias, tanto en el pasado como en el presente, ya que la relación entre los valores morales y la práctica es dinámica. Además, se pueden construir de muchas formas, y una de las más importantes es a través de la recursividad de los ejemplos (Humphrey, I997). En 
este caso, se prescriben modelos morales que son depositarios del camino a seguir, de los ideales a los que toda la comunidad debe aspirar a continuar. Por supuesto, las oposiciones dualistas (al estilo bueno/malo) constituyen reduccionismos que impiden percibir eventuales "zonas grises de ambigüedad moral" (Csordas, 2013: 535) y acceder a los criterios contingentes de aplicación de los estándares morales. Por ello, la moralidad es concebida como una "dimensión de la acción humana que puede ser más o menos pronunciada, más o menos vívidamente discernible, y más o menos urgente en escenarios y situaciones" (Csordas, 2013: 535-536). Porque, sobre todo, la moralidad es situada, y admite apropiaciones diferenciales (según género, grupos de edad, clase, asociaciones delictivas, instituciones, corporaciones etc.) no sólo entre ámbitos sino de los propios sujetos según sus contextos de ejecución.

Zigon (2008), por su parte, afirma que la moralidad es un habitus, es decir, un conjunto de disposiciones irreflexivas que se manifiestan corporizadas. Así, sólo se implementa como ese modo encarnado y cotidiano de estar en el mundo y no se sistematiza en una serie de principios y reglas. En esa línea, este autor indica además que la moralidad se reconfigura a partir de las diferentes experiencias sociales. La moralidad posee un nivel discursivo, puntualmente "aquellos discursos públicos e institucionalmente articulados", que sus enunciadores consideran como "correcto, bueno, apropiado y esperado" (Zigon, 2008: I8). Obviamente, como todo conjunto sistemático de representaciones no determina absolutamente la moralidad vivida y corporizada. Entonces, la clave para entender la moralidad radicaría en colocar el foco en aquellos momentos en los que se producen dilemas morales, es decir, cuando surgen inquietudes conscientes en torno a esa moralidad discusivamente articulada. Por consiguiente, es en el marco de esos dilemas morales en donde la ética, en tanto reflexión consciente sobre lo adecuado y aceptable, aparece como una instancia necesaria para regresar, mediante una serie de cuestionamientos, a "la comodidad irreflexiva" (Zigon, 2008: I8) del discurso moral. En esta línea teórica, el antropólogo debería buscar esas encrucijadas entre moralidad y ética, lo que permitiría advertir de qué modo la moralidad juega un rol fundamental en la vida cotidiana de las personas.

\section{"VIEJOS" ATLETAS Y “NUEVOS" RUNNERS}

Si bien en una primera aproximación podría considerarse al running como una variante de la práctica del atletismo, se trata en realidad de universos diferentes, pero que poseen evidentes y densas zonas de contigüidad. Por supuesto, se sostienen en el mismo ejercicio atlético, pero responden a formas de apropiación y subjetivación diversas por parte de los colectivos igualmente disímiles que los protagonizan. La emergencia del running, en contraste con el atletismo competitivo, no sólo implica un cambio de denominación, un mero snobismo como podría etiquetarse fácilmente. Por el contrario, el running conlleva modi- 
ficaciones sustanciales de apropiación de una actividad física puntual que ha sido llenada de contenidos profundos y diversos. Otro marcado contraste es que las competencias de atletismo de pista no gozan en la Argentina de una adhesión masiva por parte de la población y no logran atraer apoyos económicos significativos por parte del Estado, las empresas o los medios de comunicación. Incluso para muchos actores relevantes del universo running, la distinción con el atletismo parece por demás clara. Uno de los clubes de entrenamiento más notorios y numerosos de Mar del Plata se denomina "de atletismo y running". Incluso su director llama aficionados a los runners y "atletas" a quienes se desempeñan en la alta competencia.

Los runners aparecen a los ojos de no pocos atletas de alta competencia como un conjunto de actores que portan nuevos hábitos y estilos que irrumpen en el escenario atlético. Estos "recién llegados" (que ya no son tan recientes) son los que colonizarían el fenómeno, preocupados por la estética, por conocer lugares exóticos, buscar sexo con parejas ocasionales y "figurar" en las redes sociales. Algunos de esos "verdaderos" atletas manifiestan una marcada sorpresa, distancia y hasta rechazo visceral por el crecimiento de aquel "deporte de negro",3 que consistía (y para ellos sigue siéndolo de la misma manera) en una disciplina sacrificada que además carece de retribuciones simbólicas. En contraposición, los "recién llegados" han copado la escena, caretas4 y snobs que representan ese cambio irreversible.

Se trata de disputas y tensiones eventuales en torno a los valores atléticos "puros", que si bien aparecen veladas y no forman parte del imaginario hegemónico del running, no dejan de estar presentes. En consecuencia, surge la necesidad de dar cuenta de "cuáles son los lenguajes, las retóricas, los repertorios socialmente disponibles" (Noel, 2014: 20) que los diversos grupos de corredores movilizan en estas situaciones de fricción y, eventualmente, en la disputa por recursos materiales y simbólicos. Así es que como nuevo mercado del tiempo libre (Chaney, I996), esa comercialización y estilización que encarnaría el running se suele asociar con una expresión de clase (media y media alta). Como ya ha sido objeto de reflexión de la teoría social, sobre todo a partir de Bourdieu y Elias, la manera en que se emplea el tiempo libre y utilizan los bienes, configuran formas de delinear el estatus, creando vínculos y generando distinciones sociales. Siguiendo a Bourdieu, Osgerby (2006: 3I) afirma que "este habitus de las nuevas clases medias se expresa a través de una gama de comportamientos, actitudes y gustos, que abarca cada cosa desde la comida y la moda a la música y el diseño interior". ${ }^{5}$

Esas tensiones entre el atletismo y el running tienen, en ocasiones, su repercusión masmediática. En una nota del diario argentino La Nación, titulada "La falsa épica del maratón" (2 I oct. 20I6), el cronista exponía algunas inquietudes formuladas por diversos entrenadores acerca de ciertos hábitos que consideran problemáticos y crecientes en las carreras cada vez más masivas. Por ejemplo, 
en los maratones "de calle", uno de los problemas expuestos se relaciona con aquellas personas que realizan el trayecto caminando, provocando extensiones de tiempo no previstas. Ese y otros comportamientos considerados "irresponsables" fueron planteados en esa nota en la que se describe un panorama de:

corredores mal entrenados, entrenadores que aceptan a atletas no aptos físicamente, comunicadores que ponderan la heroicidad por encima de un trabajo a largo plazo, organizadores que cuentan inscriptos como si fueran ganado razones que explican cómo se le perdió el respeto a la madre de todas las carreras: los 42,195km (La Nación, 2I oct. 2016).

El texto también detalla que desde la mitad de la maratón,

aparecen los abandonos, los calambres, las descompensaciones y todo tipo de contratiempos producto de una mala aptitud física para esa prueba, sumada la falta de experiencia y mal asesoramiento profesional. Los datos son contundentes: 134 corredores arribaron antes de las 3 horas 2842 entre las 3 y las 4 horas 66I9 pasadas las 4 horas. Y el último demoró 6 h25m39s (La Nación, 2I de oct. 2016).

En las redes sociales también se suelen expresar con frecuencia estos contrastes entre el atletismo y el running. Durante la realización del maratón de 2018 en Mar del Plata, los problemas organizativos dispararon una serie de reflexiones en Facebook que pusieron en escena estas dimensiones vinculadas con la comercialización y la "superficialidad" asociada al running. Desde la biografía de una revista local de running, su editora alertó sobre "una organización desprolija, que no estuvo a la altura de lo que nuestra ciudad y todos ustedes se merecen!", destacando además el modo en que la empresa organizadora había transformado una carrera de tradición local en "una más" de un circuito comercial vinculado con una multinacional estadounidense de indumentaria. Ese posteo estimuló otras intervenciones, como la de Gabriel, quien se refirió a que "en la época de oro del maratón la gente corría y simplemente iba a correr". En la misma lógica, este corredor insistió en que "debemos replantearnos que queremos, si mas circo o empezar a correr", y remató afirmando que "hoy ya el maratón casi no le pertenece al atletismo".

Marcelo es un atleta de alta competencia de pista y de carreras urbanas y, de alguna manera, encarna todas esas tensiones entre el atletismo "puro" y el universo del running. Ha obtenido títulos provinciales en medio fondo y figura habitualmente en los primeros lugares de los campeonatos argentinos de mayores, además de obtener con frecuencia victorias y posiciones destacadas en carreras urbanas de io kilómetros en Mar del Plata y su zona de influencia. Su vinculación con el running va más allá de su participación en esas carreras "de calle" que se han hecho masivas por la asistencia de los runners, sino que él mismo es entrenador en un running team.

Ya graduado como profesor de educación física, el running se convirtió en una fuente de ingreso sustancial para poder seguir compitiendo en el alto nivel, tanto por la mencionada condición de entrenador como por los premios 
en efectivo que obtiene en las carreras urbanas. Sin embargo, en una de nuestras primeras charlas en ocasión de un viaje que realicé con el running team en el que es entrenador, no pudo ocultar un rechazo marcado a todo "el circo" del running, y en particular del trail running, ${ }^{6}$ que le parece un universo muy distante y poco interesante.

En ese sentido, Marcelo reproduce muchos de los cuestionamientos que en clave clasista se aplican al running: el snobismo de sectores medios y altos. La indumentaria utilizada en las carreras y en la preparación, y los elevados gastos que demanda participar en determinadas competencias configuran un universo moral que le es ajeno y hasta en cierta medida le resulta incómodo. Aunque deja de lado a sus entrenados de esas apreciaciones distantes, su condición de atleta de extracción social de clase baja y su concepción del atletismo lo transforman en una de las tantas figuras liminales de ese universo híbrido del running.

Por supuesto no es lo que ocurre con todos los atletas. No sólo muchos de ellos han aprovechado esta explosión del running para organizar exitosos y durables running teams, sino que también algunos pasaron del atletismo al trail running. Inclusive un corredor de fondo que llegó a consagrarse campeón argentino de maratón en dos oportunidades luego también integró el equipo nacional de trail running en diversas ocasiones, y es un habitual participante (y ganador) de carreras. Además, tiene su propio running team en la ciudad de Córdoba, cuyos miembros compiten en toda clase de carreras a lo largo del país. Leonardo, otro ex atleta de alta competencia y director de un running team considera que se trata del "combo perfecto" y rechaza algunas posturas "imbéciles" de quienes "quieren dividir porque hay espacio para todos y además también nos beneficia".

En efecto, la gran cantidad de inscriptos en esas competencias y el entorno que genera el fenómeno del running sostiene parte de los recursos que en estos casos obtienen los atletas profesionales y semi-profesionales. Aunque no está demasiado difundido, ya algunos atletas realizan "presencias", sin la necesidad de correr, en competencias auspiciadas por empresas. Montadas en la explosión del fenómeno, diversas empresas, sindicatos, ONGs, instituciones educativas, organizan competencias atléticas con premios en efectivo e indumentaria cada vez con mayor frecuencia. Como explica Leonardo, la masividad del running también termina ayudando al atletismo, o al menos así lo aprovecha para sus atletas de alta competencia. Puntualmente detalla cómo "hay una identificación de los aficionados con los éxitos de los atletas que a veces entrenan con ellos", como ocurre diariamente con los maratonistas de ese equipo.? "No sabés como se inflan el pecho cada vez que uno de ellos consigue un logro importante", destaca Leonardo.

Pero además de ello, a partir de los aficionados al running, dado que muchos de ellos gozan de un elevado capital social, se pueden montar redes de 
colaboración que redundan en la obtención de sponsors para atletas promisorios, cobertura médica cuando no poseen obra social o apoyos oficiales concretos para distintos emprendimientos. En definitiva, se trata de universos contiguos que tienen una elevada capacidad de retroalimentarse. Como sentencia Leonardo, "si lo careta sirve para que la gente haga deporte, para que el atletismo reciba también sus beneficios, ¿cuál es el problema?”.

De todos modos, hasta ese tipo de posturas encuentran sus límites en ciertos casos en que la exposición en las redes sociales de actores o grupos de running llega a niveles que se consideran extremos. Tal es lo que ocurre con los equipos de entrenamiento que organiza una multinacional deportiva. La filial argentina de esa empresa ha seguido estrategias pendulares en su significativo apoyo e identificación con el running. Más allá de los auspicios a ciertos atletas de alta competencia y la organización de carreras (modalidad que interrumpió desde 20I7), esta compañía de origen estadounidense dejó de apoyar directamente a equipos de entrenamiento en distintos lugares del país, varios de ellos liderados por reconocidos entrenadores de atletismo. Más allá de seguir vinculada a esos grupos, la compañía decidió montar sus propios running teams con lógicas de organización diferentes. Sin contar con entrenadores prestigiosos del medio atlético y con un despliegue publicitario de relieve que incluye principalmente a las redes sociales, ha llevado hasta el extremo todas las prácticas caretas con las que se suele condenar al running. A tal punto que actores relevantes del medio han confesado que esa nodalidad les "hace ruido" o incluso, un director de un running team lo definió más como una "sesión de fotos" antes que un proyecto integral de entrenamiento.

Pero más allá de estos casos extremos, esas oposiciones al running parecen destinadas a desparecer o a circular por canales subterráneos de una pequeña elite atlética sin capacidad de manejar las cuotas de poder como para imponer estigmas durables. El destino es más bien el que le cabe a Marcelo, a Leonardo y a tantos otros, de enrolarse en la poderosa red conformada en torno al running y experimentarlo como un medio de vida complementario de los ideales atléticos que son casi imposibles de mantener en su estado de "pureza". Porque esta explosión del running es además alimentada por una amplia variedad de emprendedores morales (Becker, 2009), es decir aquellos actores con capacidad de influenciar en las configuraciones morales en determinadas circunstancias, cristalizando las representaciones y prácticas correctas, eventualmente en ciertos conflictos o escenarios nuevos o problemáticos.

El objetivo de estos emprendedores puede apuntar, por ejemplo a través de campañas en los medios de comunicación, a producir cambios en las conciencias individuales y colectivas. Esta clase de actores suelen ser denominados - en el running y en otros ámbitos - como influencers, quienes operan como promotores de ciertos estilos de vida (Abidin, 20I7). Los influencers se desempeñan como “intermediarios de estas 'sensaciones personales' cuando incorpo- 
ran productos para la venta en sus vidas personales y la representación de estilos de vida a través del dispositivo infomercial" (Abidin, 2017: 165). Se trata de sujetos que tienen la capacidad - o se cree que la tienen - de influenciar a los potenciales consumidores, en este caso para la elección de determinadas carreras o para elegir cierta indumentaria o un running team. Aunque esa práctica casi ha desaparecido en las promociones de las carreras en las redes sociales, los organizadores han apelado a sujetos famosos (generalmente del mundo de la farándula) como difusores de sus competencias. Muchos de ellos se volcaron al running y promocionan su nueva afición, siendo enrolados por los organizadores y eventualmente empresas de indumentaria como caras visibles de sus campañas. No es más que una práctica habitual de las empresas que publicitan "el cambio hacia una 'vida más saludable'” (Garton \& Hijós, 2018: 26).

\section{MORALIDADES EN ACCIÓN}

Las imágenes que circulan en las redes sociales son muestras ricas de esta ética y estética runner. A través de esos discursos visuales, queda claro que los individuos no poseen "solamente una imagen y un ideal de su propia persona, sino también una imagen y un ideal colectivo, el del 'nosotros'” (Elias, 2009: I66). Como se intenta mostrar, los corredores administran una imagen colectiva que "penetra, sin disolverse, en la organización personal del individuo que, en tales casos, utiliza los pronombres 'yo' y 'nosotros' en relación con él mismo" (Elias, 2009: I66). Se trata de fotografías y dibujos que están acompañados por textos con una fuerte carga moral, construidos con frecuencia como diálogos imaginados, algunos de ellos conflictivos.

Estos discursos suelen tematizar en la condición adictiva o patológica del running, pero resignificada positivamente como marca de distinción frente a los no iniciados. Así como se puede postular que "Soy adicto a correr y no quiero curarme", también se puede sostener que "Correr es un deporte mental... y nosotros estamos locos". Por supuesto, abundan apelaciones a la exploración de los límites físicos, pero sobre todo mentales. Así como se aclara que "el límite lo ponés sólo vos", también se advierte que "ser débil es una elección. Por eso sé fuerte". Claro que también pueden encontrarse referencias más directas a una mejora en las condiciones de vida, tales como que correr "te libera del stress y mejora tu condición física". O además se aclara que "el dolor es temporal. La satisfacción para siempre". En la misma sintonía, un corredor imaginado plantea que "no entreno para una carrera en particular. No intento imponer un nuevo récord, ni sorprender a nadie. Estoy cambiando mi vida". O incluso se pueden poner en escena estas dos últimas dimensiones: "Para correr se necesita algo más que talento; se requiere la voluntad de trabajar duro y el deseo de hacer algo increíble con tu vida".

La adopcion apasionada de este estilo de vida puede llegar a tornar incompatible la sociabilidad cotidiana con la pareja, incluso de matrimonios es- 
tables con hijos. Los viajes, los horarios de entrenamiento, las dietas y las nuevas inquietudes son potenciales fuentes de tensión en las parejas que no comparten la adhesión por el fenómeno. Algunas imágenes y textos autocelebratorios del colectivo runner que circulan por las redes sociales tematizan de forma explícita esta problemática, fijando bajo ciertos límites una comunidad moral sin demasiado espacio para los no iniciados. Algunos de estos dicursos no son tan explícitos y remiten a una universo pasional que, lindante con la locura, se centran en esa supuesta incompatibilidad con los outsiders. Más allá de reiteradas apelaciones a una moral particular que coloca el énfasis en un cambio radical en el modo de vivir, "de hacer algo increíble con tu vida", otras referencias en clave humorística plantean de manera descarnada los potenciales conflictos de pareja. En una de esas imágenes de las redes, ella le plantea a su pareja: "O dejas tu adicción a correr o me voy...". Lejos de preocuparse, él le contesta "sólo una carrera más y te ayudo a empacar".

Sin contener un lineamiento discursivo unívoco y compartido, el running presenta algunas aristas salientes que giran en torno a unos pocos tópicos y estrategias enunciativas de cierta redundancia. Los dispositivos enunciativos habituales que circulan para reafirmar la identidad runner se sostienen en la construcción de un límite marcado entre quienes forman parte del universo runner y quienes no. Una de las formas de construir discursivamente ese efecto de sentido reside en la figura del enunciador objetivo "que se limita a producir de las afirmaciones sobre el registro impersonal" (Manetti, I998: I03). Así, revela principios que se asumen compartidos para el enunciatario. En estos casos se apela a la ficción legal del colectivo runner cuyas virtudes morales son destacadas de manera especial, como las vinculadas con una ética del esfuerzo, que descansa en la constancia, la humildad y la autosuperación.

En otra de las imágenes que circulan en las redes sociales y que diversas páginas especializadas y corredores en sus perfiles comparten en evidente señal de adhesión, se enfatiza en que "caer está permitido. Levantarse es obligatorio". En esa línea, en otra de esas imágenes se destaca además que "La diferencia entre lo posible y lo imposible reside en la determinación personal". La definición de los actos virtuosos de un corredor se sostiene en el esfuerzo de llevar adelante lo que se practica en sí mismo, independientemente de las habilidades que se posean. No pocos corredores, como Alfredo, se burlan de sí mismos afirmando que para lograr buenas marcas tendrían que "nacer de nuevo en otro cuerpo". Por eso, otra de las tantas imágenes con sus leyendas que circulan por las redes sociales es elocuente: "Dar cualquier cosa menor a tu capacidad, es sacrificar tu don".

Una tienda de deportes de la ciudad de Mar del Plata, que además organiza un importante circuito anual de carreras, difundió una publicidad virtual en la que sobresalen las palabras "imposible" e "inalcanzable", con los prefijos "im" e "in" tachados, mientras se divisan los pies de un corredor sobre el asfal- 
to. Otros textos configuran fuertes proclamas, en las que de forma contundente se explicita que "no esforzarse lo suficiente es sacrificar el don". Siempre focalizando en esa ética del esfuerzo que necesita la convicción del runner, se destaca que "la derrota es temporaria. Rendirse la convierte en permanente". Otro ejemplo pertinente es el lema que escogió un running team liderado por un conocido atleta de elite en el circuito de trail running: "La distancia entre querer y poder se acorta con el entrenamiento". Otra apelación no sólo es ilustrativa en el mismo sentido sino que condensa uno de los rasgos centrales del "contrato de lectura" (Verón, I985) que el running experto y convencido ofrece a todos los nativos: "El último es el más lento de los ganadores". Las referencias también abundan sobre las ventajas que el goce estético particular produce en sus cultores, aunque se suelen explorar recursos humorísticos o figuras retóricas como la ironía. Combinando la lógica de las prescripciones médicas, no son pocos los mensajes que se centran en los "efectos secundarios del running", tales como: “- Aumenta el sudor y la autoestima -Felicidad absoluta -Euforia".

Otro dispositivo enunciativo identificado emplea marcas pronominales del singular y del plural, fluctuando - en el marco de la construcción discursiva de una complicidad con el sujeto enunciatario - entre el nosotros runner y el "yo" y el "tú" runner, eventualmente este último en el modo imperativo. Se construye entonces una complicidad entre los runners que "consiste en construir al destinatario como una suerte de coenunciador" (Manetti, I998: I03). La utilización del nosotros inclusivo equivale a la suma del "yo" y el "tú" que permite atribuir la palabra tanto al enunciador como al enunciatario. A la imagen de dos corredores que cruzan un puente en direcciones opuestas y que están a punto de chocar sus manos en señal de complicidad, se aclara que "sólo nosotros nos entendemos el uno al otro". Del mismo modo, "somos los únicos que salimos a correr cuando ya estamos cansados de todo". La primera persona del singular refiere en estos casos a ese conjunto de valores compartidos de los que en este caso puntual se apropia un sujeto enunciador ideal, que toma la palabra y que, por ende, encarna al colectivo. Por ello, "elijo correr porque quiero aprender a confiar en mí mismo". O también se puede afirmar que "pensé que no iba a poder. Por suerte me equivoqué".

De manera similar, el empleo de marcas de la segunda persona del singular favorece, al menos de manera parcial, la representación de un diálogo entre el enunciador y el enunciatario. Así, podrá adjudicársele a nuestro runner ideal: "No te preocupa el clima... tienes actitud runner". Del mismo modo, "No necesitás una razón, necesitás una calle". Como también "sos corredor cuando te levantás más temprano los domingos que los días de trabajo". O más en detalle, se pueden relatar las actitividades esforzadas del corredor, especificando que "correr duele, lleva tiempo, requiere dedicación y voluntad", para concluir que "pero cuando cumplís con tus objetivos, vale la pena". Análogo argumento quedó expresado en una publicidad de un comercio de indumentaria deportiva 
para promocionar las carreras que organiza esa empresa: "La vida es como el ejercicio. Cuanto más duro es, más fuerte te vuelves”. Como se advierte, el enunciador coloca al enunciatario en el mismo plano y asume que ambos forman parte de la misma comunidad moral, dado que "un par de kilómetros por la mañana pueden cambiarte el día entero". Así, los no iniciados aparecen como espectadores de la moralidad ejemplar runner: "Que tus pisadas sean tan firmes y tan fuertes que dejen huellas. Y que esa huella sea inspiración para los demás". Y tampoco faltan las alarmas para no caer en la tentación de inccumplir con esa ética del esfuerzo: "Alquien más ocupado que vos está corriendo en este instante". Por supuesto, se deja en claro que "cuando las piernas y tu cabeza no puedan más, tu corazón hará el resto".

Otro dispositivo enunciativo frecuente en este tipo de textos descansa en la estrategia discursiva de la interpelación. Aquí, se utiliza el modo imperativo, pero no como una intimación o una orden sino como una consigna de complicidad, un consejo que refiere a un sujeto ideal que comparte las virtudes morales del propio colectivo runner. Por ejemplo, a partir de la imagen de un corredor con un cable que se desconecta de la toma de pared, surge la leyenda: "La mejor terapia. En esos momentos difíciles. Corre y desconecta". Esa variante incopora en algunos casos algunos matices de contenido. Por ejemplo, a partir de un corredor en un camino de niebla, el texto escrito sostiene: "No tengas miedo de ser diferente. Ten miedo de ser igual a los demás". En efecto, algunos de estos discursos tienen las característica saliente de incoporar un soporte adicional difuso que no sólo no forma parte de esta propuesta de diálogo sino que remite explícitamente al otro, es decir, a quien se resiste a adoptar el estilo de vida runner. De allí que algunos de estos mensajes focalicen en esa alteridad y sus falencias, que enaltezcan las virtudes morales de la autoadscripción identitaria. De allí que no sorprenda que se coloque al no iniciado en una posición tan antagónica, apelando a diversos estereotipos, tales como el perezoso, inconstante o directamente mediocre o perdedor. Se trata de discursos autocelebratorios que se orientan a provocar sentimientos adversos como la vergüenza para quienes no poseen el espíritu nececesario para volcarse hacia estas actividades virtuosas.

Esta complicidad construida discursivamente a partir del contenido combina los diferentes dispositivos enunciativos mencionados más arriba. Pueden hallarse varios ejemplos ilustrativos, tales como: "quienes dicen que estás loco por correr cinco veces a la semana, están en el sofá viendo la TV". También otro ejemplo tal vez más directo: "los ganadores se ponen metas, los perdedores excusas". Algunos de estos textos lindan con la agresividad al plantear que "las calles desiertas son mías y de mis piernas. Mientras tu duermes yo salgo a darle vida a mi cuerpo. No hay mejor descanso para un domingo que un fondo. Los domingos son I00\% runners". En los casos más extremos, la formulación sistemática de la moralidad runner postula en cierta medida una identidad en 
riesgo, amenazada por quienes no lo entienden e incluso quienes se atreven a no compartirlo. "Algunos no entienden tanto sacrificio, ipero no saben que sin eso no podemos vivir!" En ese diálogo e interpelación imaginada, puede haber espacio para una controversia con ese otro amenazante que no comprende y eventualmente discute: "le dicen suerte pero es constancia, le dicen casualidad pero es disciplina, le dicen genética, pero es sacrificio". O también referencias despectivas al supuesto cuestionamiento del estilo de vida runner: "Deciden ser ellos mismos sin importar lo que digan los demás, son persistentes en la búsqueda de sus metas, deciden vivir con pasión, son... CORREDORES".

\section{CONCLUSIONES}

En este artículo se ha analizado una de las dimensiones salientes de la práctica virtuosa de correr, tal cual la entienden los mismos runners. Se ha intentado describir en detalle el modo en que los corredores moralizan y estilizan su opción por correr. Así es que el running es presentado por sus adeptos como un estilo de vida encarnado en personas "virtuosas" que "saben" como deben actuar, a través de una transformación ética, que ofrece un amplio menú de opciones adaptables a cada proyecto personal. Esa moralidad discursiva del running también incorpora componentes utilitarios que destacan las consecuencias placenteras de ese esfuerzo. Porque el hecho de vivirlo y compartirlo con otros implica un fin en sí mismo, un acto virtuoso por excelencia en la experiencia de correr. Reemplazar al psicólogo, bajar de peso, mejorar la vida sexual, obtener placeres constantes entrenando, participando en carreras o viajando, configuran un amplio y extensible conjunto de posibilidades para darle forma a una vida "mejor" y más bella.

El running constituye un colectivo cada vez más numeroso, cuyos aficionados se entregan a un estilo de vida que promete un bienestar durable y que además constituye un eje fundamental para la conformación de identidades personales y grupales. Los corredores manejan entonces una ontología emocional (Illouz, 2007) específica, que les posibilita definir sus propios ideales que involucran distintas facetas de la vida: desde aspectos "espirituales" hasta "superficiales", desde definiciones de realización personal hasta proyectos colectivos. Socializados en gran medida en los running teams, van corporizando allí esa ética del esfuerzo que admite distintos grados de involucramiento. La cantidad y la intensidad de los entrenamientos, la incorporación de nuevos hábitos ("más sanos") alimenticios, la participación en pocas, muchas o ninguna carrera son todas dimensiones variables y sujetas a apropiaciones personales o grupales, en este último caso, cuando un running team adquiere un estilo particular.

En efecto, algunos corredores pueden incluso sostener su propia apología del running en la ampliación de un margen para comer asados y consumir cerveza mientras que otros, como ocurre con los runners más comprometidos, abandonan el consumo de carne roja y productos con gluten, pero no sólo pa- 
ra mejorar su rendimiento sino para acceder a una vida más "sana" o incluso con mayor conexión con "la naturaleza". Esa amplia flexibilidad de apropiación, que es una de las claves del éxito global del running, responde sin embargo a un conjunto de postulados comunes sobre la virtud, el esfuerzo y el bienestar, y hasta del compañerismo. A través de distintos canales de difusión, pero principalmente desde las redes sociales, se cristaliza un imaginario runner que en sus versiones más extremas postula el correr como una decisión de vida virtuosa. Además, las redes sociales se posicionan como una garantía de la masividad e intensidad del running, permitiéndole lograr tal robustez en su construcción que de otro modo demandaría mayor esfuerzo colectivo y despliegue de recursos materiales.

Envueltos en una compleja red sociotécnica, los runners hacen de la visibilidad de su estilo de vida uno de los rasgos distintivos de su cotidiano. En contraposición, algunos de esos discursos - en muchas ocasiones en clave humorística - colocan al corredor frente a un otro que condensa opciones morales condenables, tales como la pereza o la debilidad de carácter.

En definitiva, el running favorece el desarrollo de una estructura de la personalidad (Elias, 20I I) propia de nuestros mundos contemporáneos y que estimula una forma particular de individualidad. Los corredores emergen entonces como individuos que moralizan y estilizan una opción de vida y que la exponen de manera extravagante en su cotidianeidad y en las redes sociales. Y lo hacen en el marco de un estilo de vida apropiado para la implementación de las estrategias publicitarias y de diseño por parte de las empresas, siempre ávidas por promover los criterios estéticos de la moda. Pero aunque estén atravesados e influenciados por las lógicas del mercado, no por ello los runners son los reproductores acríticos de un capitalismo que promueve cuerpos y mentes disciplinadas o la búsqueda irrefrenable de distinción social y sus consecuentes aspiraciones desclasadas. Por el contrario, sus preceptos éticos y estéticos le dan forma a una serie de placeres corporizados que configuran una poderosa tecnología de autogobierno (Crossley, 2005). Como un genuino régimen de subjetivación, los corredores realizan una constante evaluación reflexiva de sus circunstancias y los factores contextuales que les permiten concebir proyectos individuales satisfactorios y durables.

Recibido en 20/9/20I8 | Revisado en 29/3/20I9 | Aprobado en 29/4/20I9 
Gastón Julián Gil es doctor en antropología social (Universidad Nacional de Misiones, 2005). Se desempeña como profesor titular de antropología en la Universidad Nacional de Mar del Plata y como investigador independiente del Consejo Nacional de Investigaciones Científicas y Técnicas. Sus investigaciones se han concentrado en problemáticas de identidad, memoria, violencia y la producción del conocimiento antropológico. En la actualidad investiga sobre el running como un estilo de vida globalizado. Autor, entre otros, de Hinchas en tránsito y Las sombras del Camelot. 


\section{NOTAS}

I Mar del Plata, además de ser el principal destino turístico de verano en la Argentina, mantiene una población estable de más de 600 mil habitantes, según datos del censo de 2010 .

2 En el caso argentino, más allá de la producción de Archetti, es relevante destacar la línea de investigación abierta por Sergio Visacovsky (Visacovsky \& Garguin, 2009) acerca de la importancia de las configuraciones morales para el establecimiento de las fronteras de clase, principalmente en torno a la clase media como instancia de autoadscripción de diversos grupos sociales. Recientemente, Noel (20II, 20I4, 20I6) se ha concentrado en la problemática de las moralidades, abordando diversos entramados urbanos en clave eliasiana bajo el modelo de los establecidos y marginados (Elias \& Scotson, 2006).

3 Un entrenador de larga trayectoria en la ciudad de Mar del Plata solía utilizar esa expresión para describir cómo, cada vez que detectaba alguna niña o adolescente de clase media, media alta o alta con marcadas aptitudes atléticas, su familia no dudaba en pensar en otras disciplinas deportivas, como el hockey sobre césped.

4 Categoría nativa aplicada en la Argentina a aquellas imposturas orientadas a fingir comportamientos y adhesión a valores legitimados socialmente. Es empleada en la actualidad por amplios sectores sociales para señalar como se expresa la hipocresía (por ejemplo, en asuntos de moralidad), pero en su acepción más extrema remite a la defensa de una ética del exceso y la rebeldía frente a una ética de la represión.

5 Si bien la problemática de clase social en el running excede los alcances de este artículo, se trata sin duda de una dimensión analítica relevante para una comprensión más profunda de este estilo de vida. Durante el trabajo de campo se ha podido constatar que la pertenencia de clase es mucho más inclusiva que lo que parece mostrar ese imaginario que asocia la opción por correr como un estilo de vida a los sectores medios y medios altos.

6 El trail running constituye un género distintivo de carreras, en contraste con las más visibles, que son las urbanas 
(como las maratones). Gran parte de esas carreras "de aventura" se realizan en zonas de montaña, cordilleranas y precordilleranas, pero también en áreas rurales y hasta en pasajes costeros.

7 En este club entrenan los dos mejores maratonistas en hombres y mujeres de la Argentina en los últimos años.

\section{REFERENCIAS BIBLIOGRÁFICAS}

Abidin, Crystal. (2017). Influencer extravaganza. Commercial "Lifestyle". Microcelebrities in Singapore. In: Hjorth, Larissa et. al. (orgs.). The Routledge companion to digital ethnography. New York/London: Taylor \& Francis, p. I58-I68.

Archetti, Eduardo. (1999). Masculinities. Football, polo and the tango in Argentina. Oxford/New York: Berg.

Archetti, Eduardo. (1997). The moralities of Argentinian football. In: Howell, Signe (org.). The ethnography of moralities. London: Routledge, p. 98-I23.

Becker, Howard. (2009). Outsiders: hacia una sociología de la desviación. Buenos Aires: Siglo XXI.

Boellstorff, Tom. (2012). Rethinking digital anthropology. In: Horst, Heather \& Miller, Daniel (orgs.). Digital Anthropology. London/New York: Berg, p. 39-60.

Borges Barbosa, Raoni. (2016). Vergonha cotidiana, ofensa moral e ressentimento: as dimensões emocionais e morais dos rituais cotidianos de interação. Revista de Estudos e Investigações Antropológicas, 3/I, p. 93-II8.

Chaney, David. (1996). Lifestyles. London: Routledge.

Collins, Randall. (2004). Interaction ritual chains. Princeton/ Oxford: Princeton University Press.

Crossley, Nick. (2005). Mapping reflexive body techniques: on body modification and maintenance. Body \& Society, I I/I, P. I-35.

Csordas, Thomas. (2013). Morality as a cultural system? Current Anthropology, 54/5, p. 523-546.

Dias, Cleber. (2017). Corrida de rua no país do futebol. Recorde, Io/I, p. I-32. 
Elias, Norbert. (20I I). El proceso de civilización. Investigaciones sociogenéticas y psicogenéticas. Ciudad de México: Fondo de Cultura Económica.

Elias, Norbert. (2009). Los alemanes. Buenos Aires: Nueva Trilce.

Elias, Norbert \& Dunning, Eric. (1992). Deporte y ocio en el proceso de civilización. Madrid: Fondo de Cultura Económica.

Elias, Norbert \& Scotson, John. (20I6). Establecidos y marginados. Una investigación sociológica sobre problemas comunitarios. Buenos Aires: Fondo de Cultura Económica.

Garton, Gabriela \& Hijós, Nemesia. (20I8). La deportista moderna: género, clase y consumo en el fútbol, running y hockey argentinos. Antípoda. Revista de Antropología y Arqueología, 30, p. 23-42.

Giddens, Anthony. (1995). Modernidad e identidad del yo. El yo y la sociedad en la época contemporánea. Barcelona: Península.

Gil, Gastón Julián. (2018). Deporte y estilos de vida. El running en Argentina. Antípoda. Revista de Antropología y Arqueología, 30, p. 43-63.

Hine, Christine. (2017). From virtual ethnography to the embedded, embodied, everyday internet. In: Hjorth, Larissa et. al. (orgs.). The Routledge companion to digital ethnography. New York/London: Taylor \& Francis, p. 2I-28.

Howell, Signe (org.). The ethnography of moralities. London: Routledge.

Humphrey, Caroline. (1997). Exemplars and rules: aspectos of the discourse of moralities in Mongolia. In: Howell, Signe (org.). The ethnography of moralities. London: Routledge, p. 25-48.

Illouz, Eva. (20I2). Por qué duele el amor. Una explicación sociológica. Buenos Aires: Katz.

Illouz, Eva. (2007). Intimidades congeladas. Las emociones en el capitalismo. Buenos Aires: Katz.

Manetti, Giovanni. (1998). La teoria dell'enunciacione. Le origini del concetto e alcuni più recenti suiluppi. Siena: Protagon Editori Toscani. 
Marcus, George. (1995). Ethnography in/of the world system: the emergence of multi-sited ethnography. Annual Review of Anthropology, 24, p. 95-II7.

Noel, Gabriel. (2016). Los llamados y los elegidos. Los cambiantes sentidos morales de la categoría "pionero" en una ciudad de la costa atlántica bonaerense. Revista de Estudos e Investigações Antropológicas, 3/I, p. 93-II8.

Noel, Gabriel. (20I4). Presentación. Las dimensiones morales de la vida colectiva. Exploraciones desde los estudios sociales de las moralidades. Papeles de Trabajo, 8/13, p. I4-32.

Noel, Gabriel. (20II). Cuestiones disputadas. Repertorios morales y procesos de delimitación de una comunidad imaginada en la costa atlántica bonaerense. Publicar en Antropología y Ciencias Sociales, I I, p. 99-I26.

Osgerby, Bill. (2006). Rapture of the deep: leisure, lifestyle and the lure of sixties scuba. In Bell, David \& Hollows, Joanne (eds.). Historicizing lifestyle. Mediating taste, consumption and identity from the Igoos to I970s. Aldershot: Ashgate, p. 88-107.

Sayer, Andrew. (2005). Class, moral worth and recognition. Sociology, 39/5, p. 947-963.

Verón, Eliseo. (1985). L'analyse du 'contrat de lecture': una nouvelle methode pour les études de positionment des suports presse. In: Les médias. Expériences, recherches actuelles, applications. Paris: Institut de Recherches et d'Études, p. 203-230.

Visacovsky, Sergio \& Garguin, Enrique (comps.). (2009). Moralidades, economías e identidades de clase media. Estudios históricos y etnográficos. Buenos Aires: Antropofagia.

Zigon, Jarrett. (2008). Morality. An anthropological perspective. Oxford: Berg. 
Palavras-chave

Estilo de vida;

etnografia;

esporte;

ética;

estética;

identidade
Keywords

Lifestyle;

ethnography;

sport;

ethics;

aesthetics;

identity.
MORALIDADE, VIRTUDE E EMOÇÕES NO RUNNING. APROXIMAÇÕES ETNOGRÁFICAS A UM ESTILO DE VIDA NA ARGENTINA CONTEMPORÂNEA

\section{Resumo}

A popularidade crescente da opção de correr como um estilo de vida vem se constituindo como uma tendência global que caracteriza nossos mundos contemporâneos. O running, tal como costumam definir seus praticantes, estrutura-se em torno a um conjunto de práticas e representações que excedem em muito uma escolha pontual de sair a correr. Essa disciplina esportiva mobiliza um conjunto de configurações emocionais que se cristalizam em determinados ideais de comportamento, relações e sentimentos que definem um "verdadeiro" corredor. Neste artigo, a partir de um conjunto diverso de recursos etnográficos, são analisados os modos pelos quais os corredores constroem um universo moral que os distingue não apenas daqueles que não adotam esse estilo de vida mas também dos que não encarnam os seus ideais virtuosos por completo.

MORALITY, VIRTUE AND EMOTIONS IN RUNNING. ETHNOGRAPHIC APPROACHES TO A LIFESTYLE IN CONTEMPORARY ARGENTINA

\section{Abstract}

The huge increase in running as a lifestyle choice has become a global trend characteristic of our contemporary world. Running, as its enthusiasts usually call it using the English term, is structured around a set of practices and representations that go far beyond a specific choice of 'going for a run.' The sport mobilizes a series of emotional configurations that crystallize into certain ideals of behaviour, relationships, and feelings that define a 'true' runner. Setting out from a diverse set of ethnographic resources, the article analyses the ways in which runners build a moral universe that distinguishes them not only from those who have not adopted such a lifestyle, but also from those who do not completely embody their supposedly virtuous ideals. 